\title{
Assessing supply chain resilience upon Critical Infrastructure disruptions: a multilevel simulation modelling approach
}

\author{
Paolo Trucco, Boris Petrenj and Seyoum Eshetu Birkie
}

\begin{abstract}
Supply chain risk management (SCRM) approaches suggest that actors in a supply chain network should consider different risk scenarios to address and mitigate supply chain risks in a better way. Overall performance of a supply chain could be severely affected by disruptions that are triggered by failures or service disruptions in the critical infrastructure (CI) systems that the supply chain relies on. Interdependencies among the CI systems and supply chains, particularly the so-called Key Resources Supply Chains (KRSC) such as food, worsen the effects as disruption and consequences propagate in the network. In order to understand such interdependencies and enhance SCRM approaches with a more holistic view, this chapter introduces a multilevel modelling approach. The economic loss impact of disruptions in CI systems and the potential effectiveness of different strategies to improve resilience in KRSC are modelled and assessed. A combination of Discrete Event Simulation and System Dynamics is used at the different levels of the simulation model. The proposed approach is demonstrated with an application case addressing the vulnerability and resilience analysis of a fast moving consumer goods supply chain against disruptions in underlying CI systems. Results of the multilevel simulation offered relevant insights toward a better understanding of the strength and dynamics of the interdependence between KRSC and CI, and consequently on resilience improvement efforts. Results help supply chain managers to prioritise resilience strategies, according to their expected benefits, when making decisions on the amount and location of resilience capabilities within a supply chain. The results strongly support the implementation of collaborative and coordinated resilience strategies among supply chain actors to direct efforts where they can be most effective.
\end{abstract}

Keywords: Supply chain resilience, Critical Infrastructure, simulation, multilevel modelling, Fast Moving Consumer Goods 


\section{Introduction}

Chile is the number one copper producer in the world. Supply of copper from Chile was disrupted in April 2014 after the earthquake and ensuing tsunami at an epicentre far from the major copper mines (e.g. Clarke \& MacDonald, 2014). The disruption was, however, mainly due to the ruined roads, power outages, and closed ports, rather than direct damage to production facilities or capacity. This real-life example demonstrates that in any supply chain the flows of materials, information and money can easily be disrupted due not only to supply or demand problems but also due to affected critical infrastructure systems that the supply chains depend on. Similarly, a recent news on Wall Street Journal also indicated that the future prices of copper was threatened by water shortage in a small town due to drought (Patterson, 2015).

Managing supply chain risks involves decision making under uncertainty on multiple parameters. Actors in a supply chain network are often required to consider multiple levels of decision to better address and mitigate supply chain risks as much proactively as possible. Such a detailed and multilevel consideration of disruption risk interactions is important because it is not sure where the sources of disruption affecting a supply chain might emanate from. As indicated in the aforementioned example, a supply chain could be severely affected by disruption in the critical infrastructure (CI) used by the supply chain. These effects are magnified due to the (inter)dependencies between CI systems and disruption propagation to Key Resources Supply Chains (KRSC), i.e. supply chains of some industries marked as critical (such as food or pharmaceuticals) which are heavily dependent on other CI.

Supply chain risk and disruption of CI are complex phenomena that are difficult to understand in real life circumstances. To evaluate resilience strategies, consequences (losses) of CI disruptions need to be quantified; this requires an adequate understanding of all the possible cascading effects within the CI and to the supply chain network level as well. Simulation modelling approaches provide a relatively simple and cheap way of representing, experimenting and designing for such phenomena. However, simulation approaches to Supply Chain Risk Management (SCRM) or critical infrastructure protection and resilience (CIP-R) which focus on just one level provide limited support for such understanding; the complex interdependences of disruptions in CI systems and on supply chains is not given enough attention in literature.

This chapter focuses on assessing the impact of CI disruptions on KRSC, the economic losses caused and the potential effectiveness of different strategies to improve resilience in KRSC. A few recent disruption incidents are used as cases for a qualitative discussion to 
demonstrate the relevance of the issue. After having briefly discussed the state-of-the-art on simulation modelling approaches in SCRM and CIP-R, a multilevel simulation modelling approach is then introduced. The proposed approach is finally demonstrated with a practical application case addressing the vulnerability and resilience analysis of a fast moving consumer goods (FMCG) supply chain under different disruption scenarios of interdependent CI systems.

\section{Mutual dependencies between SC and CI systems}

\subsection{Critical infrastructure disruption and supply chain risk}

Critical Infrastructure (CI) can be defined as those assets and systems that, if disrupted, would threaten national security, economy, public health and safety, and way of life (McNally, Lee, Yavagal, \& Xiang, 2007). Contemporary societies are increasingly dependent on availability, reliability, correctness, safety and security of CI (The Council of the European Union, 2008). The vital functions and services of CIs are supplied through networks and assets including electricity grids, roads and communication networks.

CI systems have interdependence among each other; that is, a bidirectional or unidirectional relationship exists between the states of any given pair of CI systems (Rinaldi, Peerenboom, \& Kelly, 2001). These interdependencies can be described in terms of physical, cyber, logical, and geographic types. Physical interdependency exists when an input of one CI is dependent on material/energy output of another (e.g. a rail network depends on power supply). Cyber interdependency describes the dependence of CI on information infrastructure. When elements of multiple infrastructure are in close spatial proximity, geographical interdependence occurs (e.g. joint exposure to the same natural phenomena). When an interdependence between CIs exists and is not any one of the aforementioned three classes, it is classified as logical (e.g. increased highway usage by commuters due to railway strikes and service interruptions).

A disruption of CI or SC can be described as an unplanned and unanticipated event which prevents or limits flow of material, information or money in a system (Craighead, Blackhurst, Rungtusanatham, \& Handfield, 2007). Kim et al. (2015) argued that disruptions may occur at node (i.e. facility), arc (e.g. transportation), or network (both node and arcs) level of a supply chain. Disruptions that occur at network level are much more important than the other two as they may cause severe consequences on supply chains. By focusing on disruptions at CI, this chapter discusses how resilience strategies minimise the effect of disruptions that can affect multiple actors, i.e. nodes and arcs, in a supply chain-KRSC in our case. Disruptions in a CI include information and communication disruptions, transportation, power, and other infrastructure failures, which is the main concern in this chapter. Disruptions of these CI have 
a significant impact not only on other interdependent CI but also on supply chains that utilise the CI (Ouyang, 2014; Rinaldi et al., 2001). In fact, the consequences can ripple along different CI systems and multiple supply chain levels. Societal life can be severely affected by disruptions in CI directly or indirectly as supply chains that provide inputs for human day-today activities depend on them. For example, in the aftermath of Hurricane Katrina, oil pipes and telecommunications systems failed due to power outages (Santella, Steinberg, \& Parks, 2009). Folgers coffee plants (back then owned by Procter and Gamble) in the area were hit hard by the hurricane, affecting coffee supply. Even worse was the lack of access for the recovery effort in the area due to damaged roads, which forced them to use helicopters.

\subsection{Supply chain resilience}

Tang (2006) describes different robust SC strategies that aim to improve a firm's capability to manage supply and/or demand better under normal circumstances and to enhance the firm's capability to sustain its operations when a major disruption hits. The majority of these strategies rely on the availability of infrastructure systems that serve the supply chain, either as primary subject of intervention or as subsequent objective associated to other categories of risks. We can say that disruptions of such infrastructure represent one of the most important risk category and their improvements enable to protect SC from either CI disruptions or all the other risk categories closely linked to them.

In general, resilience can be understood as the ability of a global supply chain to anticipate, reorganise and deliver its core function continually, despite the impact of external and internal shocks to the system (Birkie, Trucco, \& Kaulio, 2014; Ponomarov \& Holcomb, 2009; Tang, 2006). Sheffi (2007) describes resilience as the capacity to be better positioned than competitors to deal with and to gain advantage from disruptions. These definitions essentially focus on capabilities that a supply chain has in mitigating disruptions happening somewhere in the network (Kamalahmadi \& Parast, 2016) and possibly turn them into an opportunity to gain competitive advantage. At supply chain network level, resilience can be seen as an attribute to withstand such disruptions triggered at a node (facility) or an arc (transportation) (Kim et al., 2015) as the consequences of a disruption at one point can ripple along the supply chain (Ivanov, Sokolov, \& Dolgui, 2014).

Rice and Caniato (2003) identified flexibility and redundancy as two broad strategies for SC resilience. Flexibility entails creating capabilities within the organization to redeploy some existing and previously committed capacities from one area to another (to make up for lost or delayed capacity). Redundancy, by contrast, is the additional capacity that would be used to 
replace the capacity loss caused by a disruption (Rice \& Caniato, 2003). Both approaches require investments in infrastructure and resources prior to the point of need.

When evaluating effectiveness of resilience strategies applied to specific parts of the SC, we also consider different levels of resilience capacity, achievable through either flexibility or redundancy, or most typically a mix of the two.

\subsection{Review of relevant SC risk and CI disruption cases}

The Chile copper supply disruption situation mentioned earlier is one demonstration of how supply chain disruptions are caused or worsened by failure in the CI systems that the supply chain depends on. Similar cases that reveal how supply chains are vulnerable to disruptions in CI systems and cascading effects are reported in Table 1.

To start by reciting the Chile earthquake situation, the main cause of copper supply shortage was not damage at the copper mines. The epic centre of the earthquake was not very close to copper mines, which are mainly located in Northern Chile. In fact, the major mining companies have announced shortly after the quake that the mines and smelting plants were intact. It was, however, difficult to transport the produced copper due to the damaged roads and power interruption. Some of the mines have also stopped production for a while because employees were sent to join and support families affected by the earthquake and the subsequent tsunami.

Large amount of mostly perishable items have been stranded at US West Coast ports during the 2002 dock workers strike. Items supposed to be delivered for Christmas sales season were delayed, and partly spoiled. The US economy as well as large retailers had to bear enormous consequences (Hall, 2004).

During the Great Japan Earthquake in 2011, automotive and electronics manufacturers felt the pain of the natural disaster. Even those companies with no physically damaged facilities or whose Japanese suppliers could still produce parts had to deal with shortages due to power outages, failed roads, sea ports and airports (e.g. MacKenzie, Santos, \& Barker, 2012; World Economic Forum, 2012).

The 2015 migration crisis in Europe, which has exacerbated since late 2015, has caused severe disruptions to logistics and custom services to several European centred supply chains. It has caused enormous disruption to the medical and other essential supplies. Some European countries blocked or tightened security at their borders, which, together with the influx of migrants, caused extremely long traffic jams. The United Kingdom alone incurred 1 billion USD a year due to the supply chain disruption because of the crisis (2015). 
Table 1. A few supply chain disruptions and their dependence on CI failures

\begin{tabular}{|c|c|c|c|}
\hline Supply chain disruption & Related/underlying CI interdependences & Disrupted CI & Consequences of the disruption \\
\hline $\begin{array}{l}\text { 1. Copper supply shortage } \\
\text { in Chile (2014) }\end{array}$ & $\begin{array}{l}\text { Supplies could not be transported due to } \\
\text { damages to roads and power interruptions } \\
\text { because of earthquake; employees of } \\
\text { mines went to families }\end{array}$ & $\begin{array}{l}\text { Road transport } \\
\text { Power supply } \\
\text { Rail transport } \\
\text { Manpower } \\
\text { Ports }\end{array}$ & $\begin{array}{l}\text { Copper prices showed increases up to } \\
\text { as high as } 1 \% \text { on London Metal } \\
\text { Exchange and New York Mercantile } \\
\text { Exchange in speculation of shortages } \\
\text { (Clarke \& MacDonald, 2014). }\end{array}$ \\
\hline $\begin{array}{l}\text { 2. Delay of essential goods } \\
\text { including medical } \\
\text { supplies in the EU due to } \\
\text { migration crisis (2015) }\end{array}$ & $\begin{array}{l}\text { Border closures and tighter controls to } \\
\text { deal with chaos due to stowaways meant } \\
\text { that the supplies were severely disrupted, } \\
\text { especially those urgently needed }\end{array}$ & $\begin{array}{l}\text { Road transport } \\
\text { Rail transport }\end{array}$ & $\begin{array}{l}\text { Great Britain alone lost an estimate of } \\
\text { at least } 1 \text { billion USD a year due to the } \\
\text { crisis (BSI, 2015). }\end{array}$ \\
\hline $\begin{array}{l}\text { 3. Auto and electronics } \\
\text { parts shortage following } \\
\text { the triple disaster in } \\
\text { Japan (2011) }\end{array}$ & $\begin{array}{l}\text { The damaged power and transportation } \\
\text { infrastructures had greatly influenced } \\
\text { recovery from the disruption }\end{array}$ & $\begin{array}{l}\text { Airfreight } \\
\text { Power supply } \\
\text { Water supply } \\
\text { Road transport } \\
\text { Ports } \\
\text { Manpower } \\
\text { Gas and fuel supply }\end{array}$ & $\begin{array}{l}\text { The direct economic impact of the } \\
\text { disruption is estimated to be more than } \\
\text { 22billion USD excluding damages to } \\
\text { damaged buildings and infrastructure } \\
\text { (e.g. World Economic Forum, 2012). }\end{array}$ \\
\hline $\begin{array}{l}\text { 4. Import items to US } \\
\text { stranded at ports (2002) }\end{array}$ & $\begin{array}{l}\text { Workers' strike caused the blockage; } \\
\text { airfreights (as alternative routes) became } \\
\text { more expensive than they usually are as } \\
\text { few fast companies already leased the } \\
\text { capacity }\end{array}$ & $\begin{array}{l}\text { Port } \\
\text { Airfreight } \\
\text { Manpower }\end{array}$ & $\begin{array}{l}\text { Retrospective analysis estimated more } \\
\text { than } 1 \text { billion USD per day for } \\
\text { economic loss to US economy for } \\
\text { each day of strike that went for } 11 \\
\text { days (Hall, 2004). }\end{array}$ \\
\hline
\end{tabular}


The aforementioned cases show how much modern global supply chains are vulnerable to failures or unavailability of CIs, such as road transport, ports, electrical power, water supply, fuel and gas supply. The vulnerability and the associated consequences becomes much more severe when we consider key resource supply chains, such as food or pharmaceutical products. We will get back to that in later sections when we discuss the simulation model. Before that, let us briefly look at modelling and simulation approaches used in SCRM and CIP-R research.

\section{Simulation modelling approaches in SCRM and CI}

Inheriting from the broader supply chain management domain, three main simulation modelling approaches are used in SCRM and resilience. These are: Discrete Event Simulation, System Dynamics and Agent Based Modelling (Fahimnia, Tang, Davarzani, \& Sarkis, 2015; Owen, Albores, Greasley, \& Love, 2010; Tako \& Robinson, 2012; T. Wu, Huang, Blackhurst, Zhang, \& Wang, 2013). We conducted a literature search and reviewed the use of the three approaches depending on the nature, goal and aggregation level of phenomena modelled. Discrete Event Simulation (DES) is process-centric (mid-low abstraction level) and facilitates the simulation of interdependent systems through occurrence of time-dependent discrete events that approximate real-world processes. System Dynamics (SD) is a rigorous top-down approach, with high abstraction level, used for modelling the behaviour of a complex system over time (Sterman, 2000). Stocks (the accumulation of resources in a system), flows (the rates of change that alter those resources), and feedback are the central concepts in this approach. Agent Based Modelling (ABM) approach allows for emulating emerging behaviours resulting from the interaction of autonomous agents (bottom-up approach) (e.g. T. Wu et al., 2013).

We extended the literature search to review the use of the same or compatible approaches for simulation modelling of CI systems, identifying their main advantages and drawbacks. This is described in the following sub-sections.

\subsection{Simulation modelling in SCRM}

Tako and Robinson (2012) analysed simulation modelling approaches used in 127 journal articles published between 1996 and 2006. Their work was based on the belief that SD was mostly used to model problems at a strategic level, whereas DES was used at an operational/tactical level. The aim of the review was to test if this hypothesis was true. The paper explored the frequency of application of DES and SD as modelling tools for decision support systems in the domain of SC Management by looking at the nature and level of issues modelled. The findings suggest that DES has been used more frequently to model SC, with the exception of the bull-whip effect which is mostly modelled using SD. The study concluded that 
in terms of the level of decision making (strategic or operational/tactical) there is no difference in the use of either DES or SD.

Owen et al. (2010) did similar literature review referring to the three approaches (DES, SD and $A B M)$ used in the papers reviewed. A total of 439 peer-reviewed papers were identified and then a sample of 100 papers was selected, reviewed and classified (Owen et al., 2010). This review revealed that both SD and ABM have been equally used to address strategic issues. DES, on contrary, was more heavily weighted towards planning problem types and was also the only approach to have been used to address operational problems.

It can be observed how the SC modelling applications in the period 2007-2010 influenced the picture as a whole. In addition, the results of our search showed examples underlining how the use of SD in the last years mostly focused on the strategic view (e.g. Ivanov \& Sokolov, 2013; Kumar \& Nigmatullin, 2011). An increase of using quantitative and analytical modelling approaches, including simulation in risk management is observed particularly after 2005 as evidenced by relatively large number of SCRM papers with modelling methodologies (Fahimnia et al., 2015).

The bibliography dealing with simulation approaches applied to SCRM theme is generally sparse. We did a literature search on the simulation approaches applied to model and analyse supply chain risk and resilience using the keyword combinations shown in Table 2a and we found very limited number of publications. Based on our last search with the keyword combinations on Scopus, (dated 14 February 2016), only 19 journal articles and 16 conference papers were found to be relevant after filtering for duplicates and relevance of content. Of the three simulation modelling approaches in SCRM, ABM seems to be relatively limited. We identified only 5 journal articles and 3 conference papers implementing this approach. Many of the publications discussed risk at supply chain network level, even though some had analysis at shop floor or inside a supply chain facility. For example, Wu et al. (2013) model risk of stockout at retailers to model the individual behaviour of competing manufacturers using ABM, it considers the customers as autonomous entities making their own decision towards the purchase of competing products. The supply chain risks discussed in the different studies are often assumed to have been "externally triggered" and not deliberate acts of the autonomous supply chain actors. Perhaps this could be a reason why ABM was limited in the papers.

\subsection{Modelling approaches in CIP-R literature}

When it comes to CIP-R, Ouyang's (2014) review on modelling and simulation of interdependent infrastructure systems provides the dominant approaches in research 
publications, including ABM, SD, and DES, as well as some other variants. In this domain, we found a relatively higher number of publications that applied one of the three simulation techniques (see Table 2b) compared to that of SCRM. Especially SD seems to be used more dominantly. All of the abovementioned papers focus on simulation modelling and analyses at supply chain network level mainly, or consider only the failures of CI systems. Some papers discuss different simulation approaches for SC risk modelling and analysis due to failure in CI (e.g. D. Wu \& Olson, 2008; Yang \& Wu, 2007). However, most of them tend to assume the CI failure simply as the given trigger that has a single point disruption impact on the supply chain. Therefore, there is a clear lack of studies implementing simulation modelling approaches to better represent the real complexity and dynamics of interdependencies between CI and supply chain.

Table 2. Literature search on the three simulation modelling approaches (a) in SCRM, and (b) in CIP-R

\begin{tabular}{|c|c|c|c|}
\hline $\begin{array}{l}\text { Simulation modelling } \\
\text { approach in SCRM }\end{array}$ & $\begin{array}{l}\text { Articles in } \\
\text { journals }\end{array}$ & $\begin{array}{l}\text { Conference } \\
\text { papers }\end{array}$ & Total \\
\hline DES & 8 & 7 & 15 \\
\hline $\mathrm{ABM}$ & 5 & 3 & 8 \\
\hline SD & 6 & 6 & 12 \\
\hline Total & 19 & 16 & 35 \\
\hline \multicolumn{4}{|c|}{$\begin{array}{c}\text { Search keywords: \{ "supply chain risk" OR "supply chain disruption" } \text { AND \{ “discrete event } \\
\text { simulation" OR "agent based model*" OR ("system dynamics" AND "Simulation")\} }\end{array}$} \\
\hline $\begin{array}{l}\text { Simulation modelling } \\
\text { approach in CIP-R }\end{array}$ & $\begin{array}{l}\text { Articles in } \\
\text { journals }\end{array}$ & $\begin{array}{c}\text { Conference } \\
\text { papers }\end{array}$ & Total \\
\hline DES & 1 & 6 & 7 \\
\hline ABM & 8 & 11 & 19 \\
\hline SD & 13 & 9 & 22 \\
\hline Total & 22 & 26 & 48 \\
\hline \multicolumn{4}{|c|}{$\begin{array}{c}\text { Search keywords: "critical infrastructure" AND \{ “discrete event simulation" OR ("agent } \\
\text { based model*” AND simulation) OR ("system dynamics" AND "Simulation")\} }\end{array}$} \\
\hline
\end{tabular}

\section{A multilevel modelling approach}

The different simulation approaches have differences in their underlying assumptions, strengths and implementation frameworks. It has been however recognised that many management decision making problems may require more than one possible viewpoint, even at the same level of abstraction, to accommodate different frames of reference and reduce risk of missing some relevant aspects (Brailsford, Churilov, \& Dangerfield, 2014; Pidd, 2003).

For example, most modelling approaches to CIP-R are motivated by decision making for better protecting CI systems that the dependency with KRSC are not well addressed (Conrad, 
LeClaire, O’Reilly, \& Uzunalioglu, 2006; Santella et al., 2009). Creating a multilevel (hybrid) model that combines different approaches in a uniform framework enables to better represent and understand complex systems (Brailsford et al., 2014; Ouyang, 2014) such as interdependent CI and KRSC. In the context of this chapter, by multilevel modelling we are referring to what is described as multiscale and multimethod modelling in Brailsford et al. (2014).

Being cautious about the differences, experts in the field have recognised the benefit of having multimethod, multilevel simulation modelling for managerial decision making. In fact, the different chapters in Brailsford et al. (Brailsford et al., 2014) provide empirical evidence of how different modelling approaches could be used complementarily or as alternatives. Recent developments in multimodel simulation software packages, such as Anylogic ${ }^{\circledR}$, appears to support efforts in this direction.

The conceptual model proposed in this chapter seeks to represent three levels (see Figure 1): the physical interdependencies between different CI systems, the relationship between possible CI service disruptions and the availability of critical resources and services for the different actors of the SC, and finally the dynamic behaviour of the KRSC as a whole. In figure 1 , the arrows indicate directional dependence/interdependence of different CI and KRSC components. The output variable represents the performance of the KRSC in generating turnover, given the abovementioned dependencies and the resilience capabilities of the SC actors.

The model applies the hierarchical method wherein the lower level model runs and generates data which is used by a higher level model, which again informs the lower level.

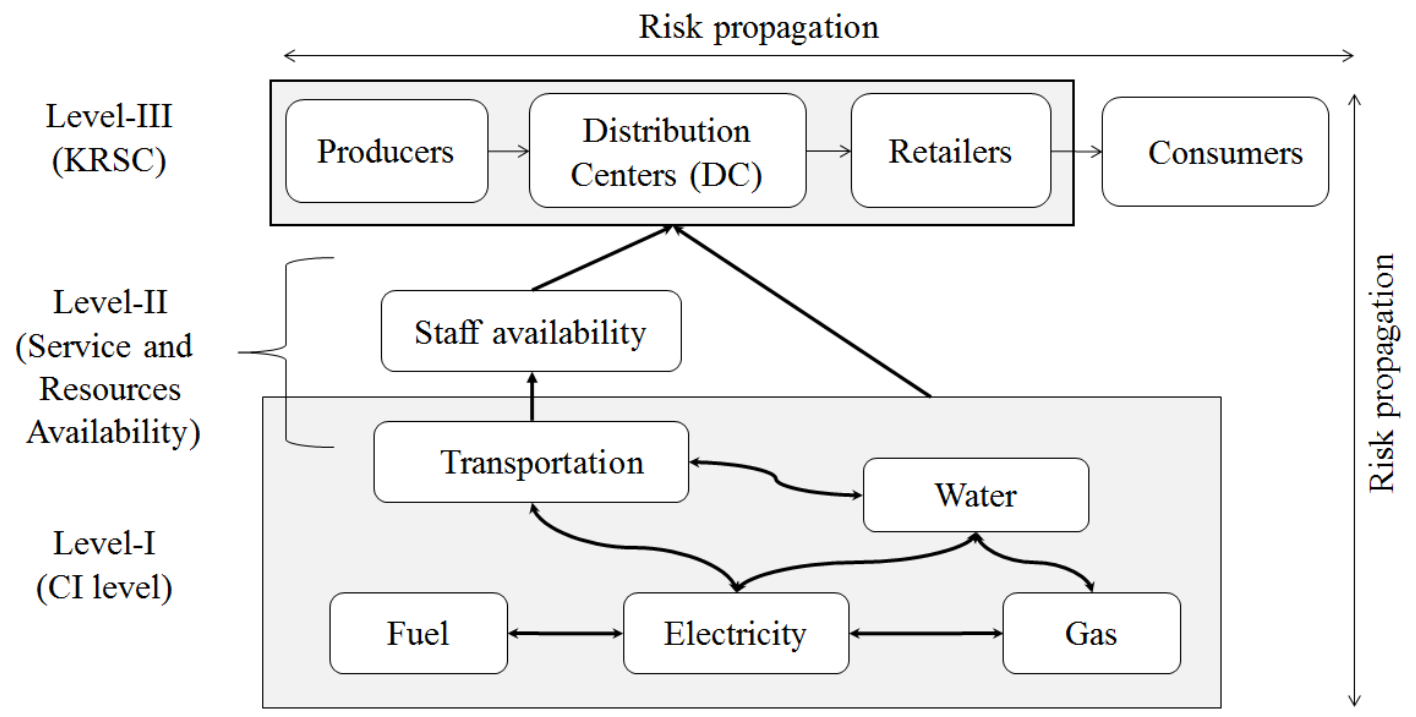

Figure 1. Multilevel simulation modelling framework 
In our model, we have chosen DES and SD simulation approaches. DES was chosen as it is very appropriate to represent phenomena which are event based involving queues, lead times, etc. The third level (KRSC) has these features, making DES appropriate. We primarily assume that the behaviour of the overall interdependent system involving the CI can be explained by the feedback nature of causal relationships that characterise the structure of the system (Brailsford et al., 2014). In SD “agents” can be homogenously mixed and aggregated to the higher level. Thus, to model the first and second levels in our study, SD is preferred over ABM which models individual agent behaviour that may evolve heterogeneously.

\subsection{The first level: Critical infrastructure}

In the first level, we can find the different CI systems and their sub-models of supply. The level was built using System Dynamics methodology (Figure2 (a)) and is composed by the following sub-models:

- Sub-model of fuel supply through pipeline;

- Sub-model of fuel supply through road and rail;

- Sub-model of gas supply through pipeline;

- Sub-model of water supply through pipeline;

- $\quad$ Sub-model of power supply.

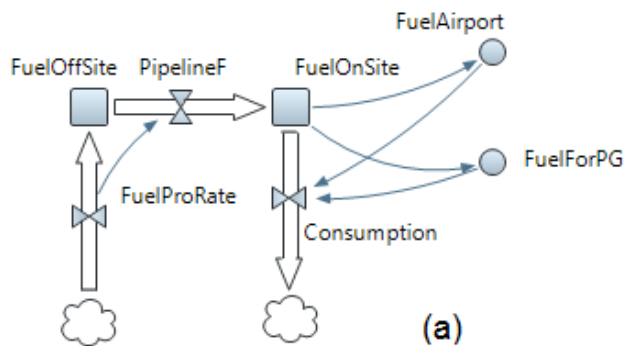

(a)

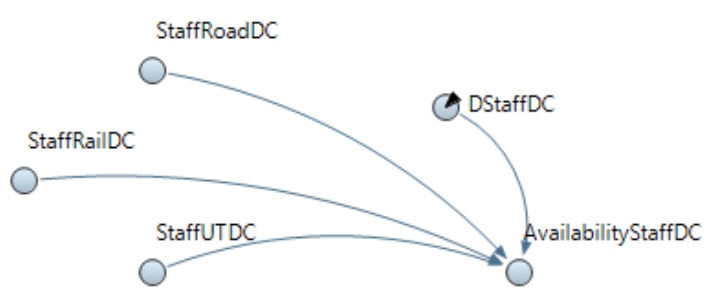

(b)

Figure 2. An example sub-model of (a) fuel supply through pipeline; (b) Staff availability at distribution centres

\subsection{The second level: service and resource availability}

The second level models the availability of services supplied by CI and of other resources used either for the KRSC or for the first level needs. This level was built with SD methodology as well. As example, Figure 2(b) shows the computation of the total staff availability at the distribution centres, taking into account the staff which uses railway (StaffRailDC), road (StaffRoadDC), or the urban train (StaffUTDC) transportation systems to reach the workplace.

\subsection{The third level: KRSC model}

The third level represents the KRSC model. It embodies the internal production and logistic phases, the import SC and the connection between distribution centres (DC) and Retailers. This 
level was built with a multimethod approach. Indeed, the initial part of the SC, in which we can find the flows of the internal and external productions (import rate), implements a SD approach. The part of the SC between the DC and retailers was modelled with DES instead. The rationale for adopting a multimethod approach is that, on one hand it assures a continuous systemic view of the dependencies from the upper levels, while, on the other hand, DES better models the capacity and lead times involved in the distribution and delivery processes.

\subsection{Multilevel model assumptions}

There are some key assumptions at the basis of the overall modelling approach:

- The model is isolated from outer environment, which means it can only be affected by inner entities (concepts);

- The physical dependencies between CI systems and other services is linear. For example, if 100 ton per day [t/d] of fuel is required to support $100 \%$ of generation capacity of a power plant, then $80 \mathrm{t} / \mathrm{d}$ of fuel supports $80 \%$ of the same capacity;

- The amount of KRSC demand is constant (i.e. an average day is simulated).

Coherent with the abovementioned assumptions, the multilevel model is able to implement inter-dependencies between CI systems. In our specific application, power generation plants and airports need fuel and/or natural gas. Furthermore, fuel is also used by road transportation. On the other side, power is used for fuel and gas production, urban transport service, water supply, road, railway, and air transportation. Staff availability is influenced by the status of urban transport system, road, and railway systems. As for the FMCG sector, the production rate is influenced by power and fuel, while the distribution process is affected by staff availability and three kinds of transportation: road, railway and air. Finally, the purchasing rate is influenced by staff availability and power.

\section{Pilot application: the Italian fast moving consumer goods supply chain}

FMCG supply chain deals with the delivery of non-durable goods, such as drinks and grocery items. At the consumer side, the main characteristics of these products are: high frequency purchase, low prices and low involvement. Looking from the producers and distributors side, the main characteristics of these products are low contribution margin, extensive distribution network and high stock turnover. A key issue in managing this type of supply chains is the perishability of the products and thus the lead-time that these goods can undergo.

The model of the FMCG supply chain consists of the following actors (Figure 1, level III):

- Producers (P) - can be classified considering both the firm dimensions (Big vs. Small and Medium producers) and the typology of products (Food vs. Health \& Care); 
- Distribution Centres (DC) - retailers' facilities for temporary storage with the main function of receiving daily orders from the retailers and deliver them to the purchasing organization that will buy the products required (e.g. warehouse or other specialised buildings);

- Retailers (R) - subjects who receive goods in large quantities from the Distribution Centre, and then sell smaller quantities to the consumer for a profit (e.g. Supermarket);

- Consumers (C) - persons who pay for the products intended for private consumption.

The model of FMCG Supply Chain as it was implemented in Anylogic ${ }^{\circledR}$ is partially presented in Figure 3. In part (a) of the figure, an implementation of SD is shown, representing flow of imported and locally produced FMCGs to the DC using different modes of transportation (rail, road, air). Part (b) of the figure shows DES implementation to model the flow of goods from Distribution Centres to Retailers.

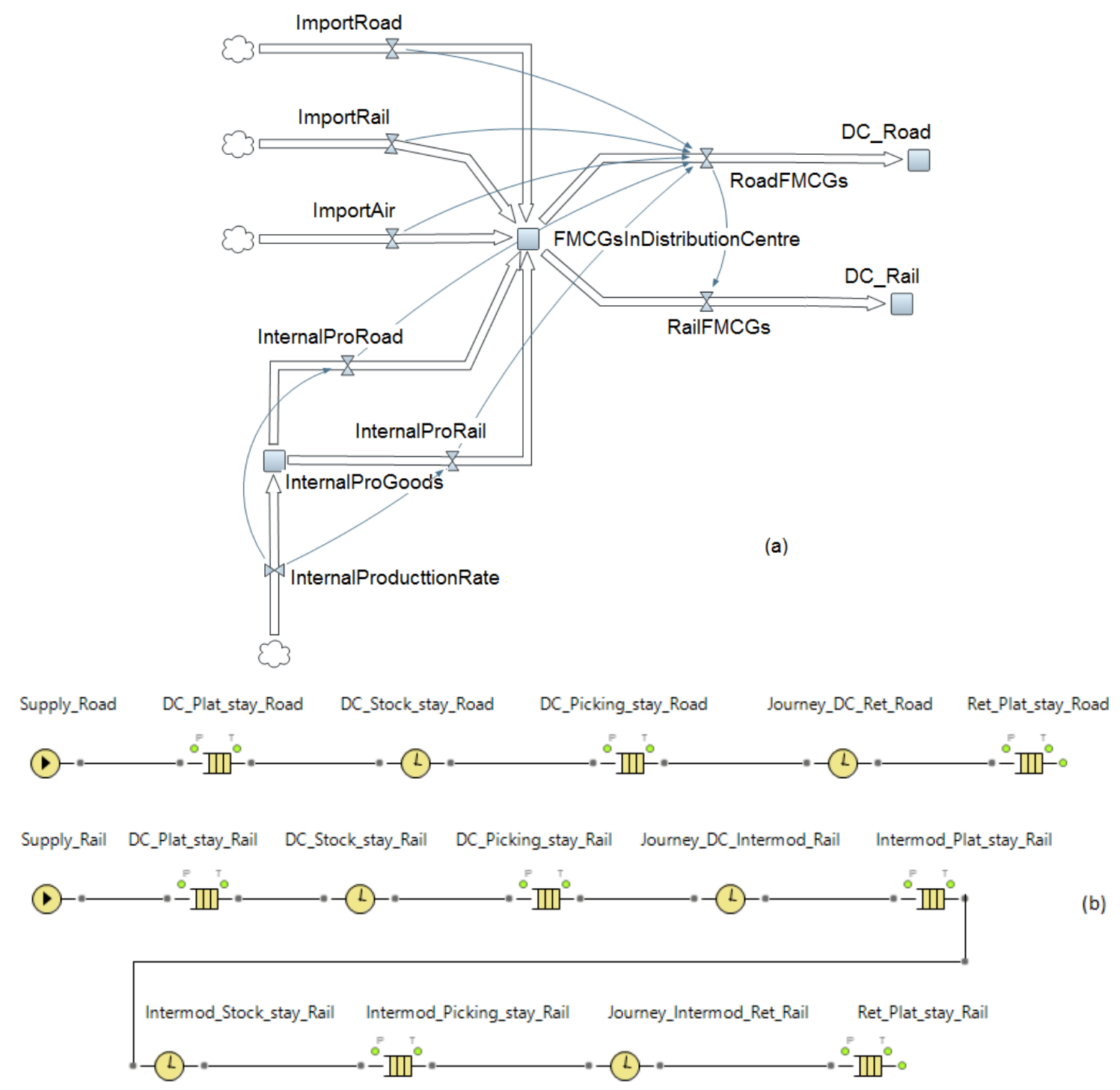

Figure 3. FMCG supply chain model implementation in Anylogic ${ }^{\circledR}$ (a) SD model, (b) DES model 
In our analysis, we considered that the lead-times between the Distribution Centre and the final retailers for different product categories vary between 7 and 12 days (these figures represent the expected mean lead-time values assured by logistics service providers for the Italian FMCG sector).

\subsection{Resilience strategies and capacities}

In face of a disruption, resilience capabilities to mitigate disruptions at the first level CI namely, gas, fuel, power generated and water - can be exploited at the three segments of the SC. The downstream segment, which includes the part of SC between DC and Retailers, the midstream segment dealing with the logistics from Producers to DC, and the upstream segment, dealing with production planning and management within the Producers. We assume that the part of SC dealing with import is not modifiable in the short range, thus its contribution to SC resilience is negligible.

The strategies represent the package of actions that SC managers and other company managers can actuate in order to sustain the business continuity of a specific segment of the SC. In particular, four basic strategies were identified and investigated:

- Strategy 1 - Exploiting resilience capabilities within just one of the supply chain members located in the upstream or downstream segments of the supply chain (e.g. resilience capabilities of retailers only);

- Strategy 2 - Extends resilience capabilities of strategy 1 to a pair of supply chain members located in the upstream or downstream segments of the supply chain (resilience capabilities of both retailers and producers);

- Strategy 3 - Exploiting resilience capabilities of triple supply chain members in the network by extending strategy 2;

- Strategy 3 plus water - This strategy adds a resilience capability of restoring some level of water supply disrupted at the producer. The justification to include this element is that restoring disrupted water supply is relatively low investment compared to the other CI services (e.g. water tanks installed at production site). We intend to observe the marginal effect of having this additional capability on recovered turnover. Hence, this strategy applies to scenarios where resilience capability of a producer is invoked.

A further dimension covered in the simulation deals with the capacity level (or strength) of the resilience capabilities activated under different strategies. In particular, three levels of resilience capacity were considered for each strategy: 
- Resilience capacity of $20 \%$ - i.e. a capacity able to mitigate up to $20 \%$ reduction of critical services due to some CI disruption;

- Resilience capacity of $50 \%$ - i.e. a capacity able to mitigate up to $50 \%$ reduction of critical services due to some CI disruption;

- Resilience capacity of $90 \%$ - i.e. a capacity able to mitigate up to $90 \%$ reduction of critical services due to some CI disruption.

Consequently, a 20\% reduction of critical services at some point of the FMCG SC is the minimum "trigger level" for the activation of the available strategies and capacities along the entire SC.

\subsection{Data specification and collection}

The initial set of data was collected from Eurostat (Directorate-General of the European Commission), namely:

- European shares of electricity, gas and water supply;

- European shares of railway, road and pipeline transportation;

- Input-output data related to:

o Manufacture of coke, refined petroleum products and nuclear fuels;

o Electricity, gas, steam and hot water supply;

o Land transport and transport via pipelines;

o Air transport;

- Total turnover per single infrastructure sectors in Italy;

Input value of single infrastructure sectors to the FMCG supply chain in Italy;

- Consumption (per year) of electricity, fuel, gas and water by DC, retailers and transport infrastructures;

- Flow rates (per year) of fuel, gas, water and goods through pipelines and/or roads, rails and air;

- Production and procurement rates (per year) in FMCG supply chain in Italy;

- Desired staff at different segments of the FMCG supply chain.

From Eurostat data, the conversion factors for each CIs were also estimated, i.e. coefficients to transform physical units, such as litres gas per year, kilograms of fuel per year, kilowatt-hours of electricity per year, litres of water per year, into a common unit of euros per year. This computational approach enabled the merging of sub-models and the definition of a unique economic indicator to measure the performance of the entire system-of-systems in terms of annual turnover. 


\subsection{Simulation plan}

Four simple crisis scenarios were defined, dealing with the disruption of each one of the CIs at the first level: (1) 50\% gas disruption for 5 days; (2) 50\% fuel disruption for 5 days; (3) $50 \%$ power generation disruption for 5 days; and (4) 50\% water disruption for 5 days.

For each disruption scenario the four strategies were applied independently at different resilience capability levels (20\%, 50\%, and 90\%), thus generating 48 different crisis scenarios to be simulated. The reference scenario (baseline), corresponding to the full availability of all the critical services, was finally added to complete the list of planned experiments. Due to the presence of stochastic processes in the FMCG SC, introduced by triangular distributions of lead-times, 20 replications covering a time window of 100 days (after 10 days of warmup run) were used to estimate the average performance values of each scenario.

\section{Results of simulation experiments}

\subsection{Reference scenario (no disruption)}

Under standard demand and nominal operational conditions, the Italian FMCG supply chain generates an average daily turnover of 37673 million euros (M€), according to our model (baseline). If referred to the contribution of FMCG sector to the Italian GDP in the years 20082012 (INIS, 2015), the absolute percentage error of our model ranges from $-2.3 \%$ to $+2.9 \%$, with a mean absolute percentage error (MAPE) of $-0.2 \%$.

\subsection{Full disruption (worst case) scenarios}

The aim of the second scenario simulated is to assess the impact on the FMCG supply chain of a disruption occurring to each of the CI systems belonging to the first level, where $50 \%$ of service is lost for 5 consecutive days. Results are shown in Table 3. The change $(\Delta)$ in turnover and recovered turnover percentage are based on the reference scenario of no disruption (baseline turnover = $37673 \mathrm{M€}$ ).

Table 3. Worst case scenarios with 5 days of CI disruptions

\begin{tabular}{|c|c|c|c|c|}
\hline Disrupted CI & Fuel & Gas & PG & Water \\
\hline Average turnover for 100 days [M€] & 33518 & 33073 & 34373 & 33504 \\
\hline Average $\Delta$ in Turnover [M€] & 4155 & 4600 & 3300 & 4169 \\
\hline Average turnover loss [\%] & $11.0 \%$ & $12.2 \%$ & $8.8 \%$ & $11.1 \%$ \\
\hline
\end{tabular}

It can be seen that the CI with the heaviest impact on the FMCG SC was gas, causing the major amount of turnover loss (4.6 billion Euros or 12.2\% of baseline scenario in the course of 100 days). On the contrary, power generation (PG) presented the least severe consequences 
among the four. Fuel and water unavailability had almost similar impacts on the economic performance of the FMCG SC.

\subsection{Disruption of CI with different levels of resilience capacity}

This final step is intended to estimate the expected benefits from the application of the four strategies, in their multiple configurations, with different resilience capacity levels (20\%, 50\% and 90\%). As stated earlier, each simulation run had warm-up time of 10 days, and lasted 100 days with a $50 \%$ unavailability of a single critical service during 5 consecutive days. Results related to the disruption of the four CI systems are depicted in Figures 4-7. The available resilience options are reported in decreasing order of effectiveness (i.e. increase in the total turnover loss in reference to the baseline). The notions used in the figures are described in the notes of Table 4 where a summary of the simulation results is given.

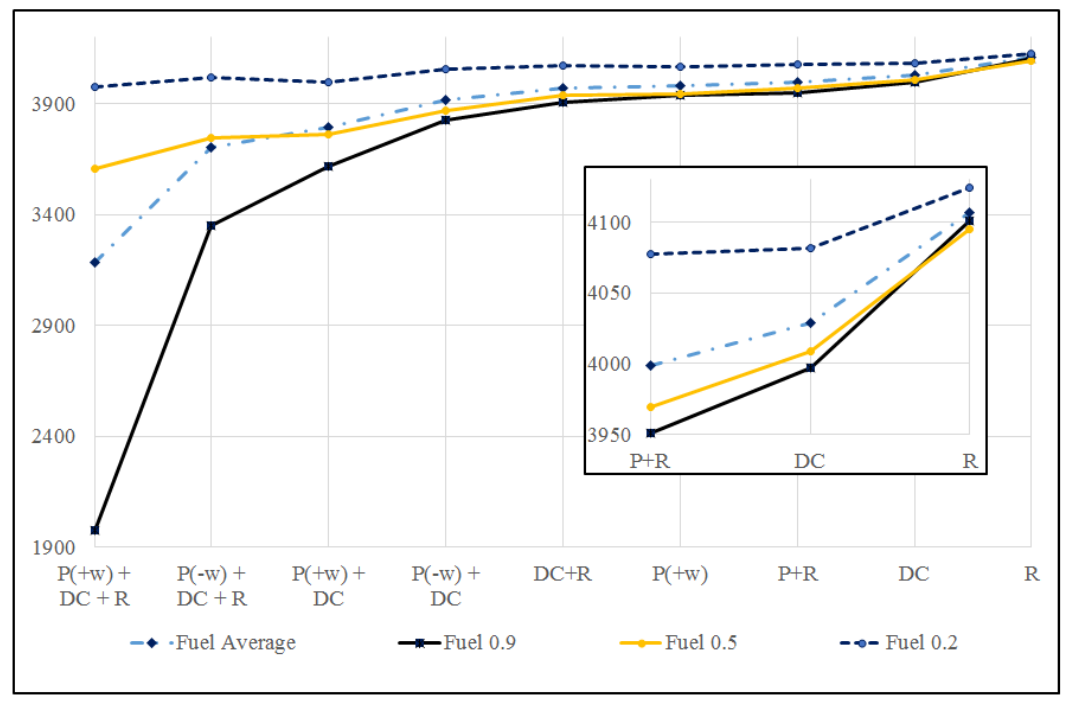

Figure 4. Average $\Delta$ turnover with 5-day fuel disruption at different resilience levels

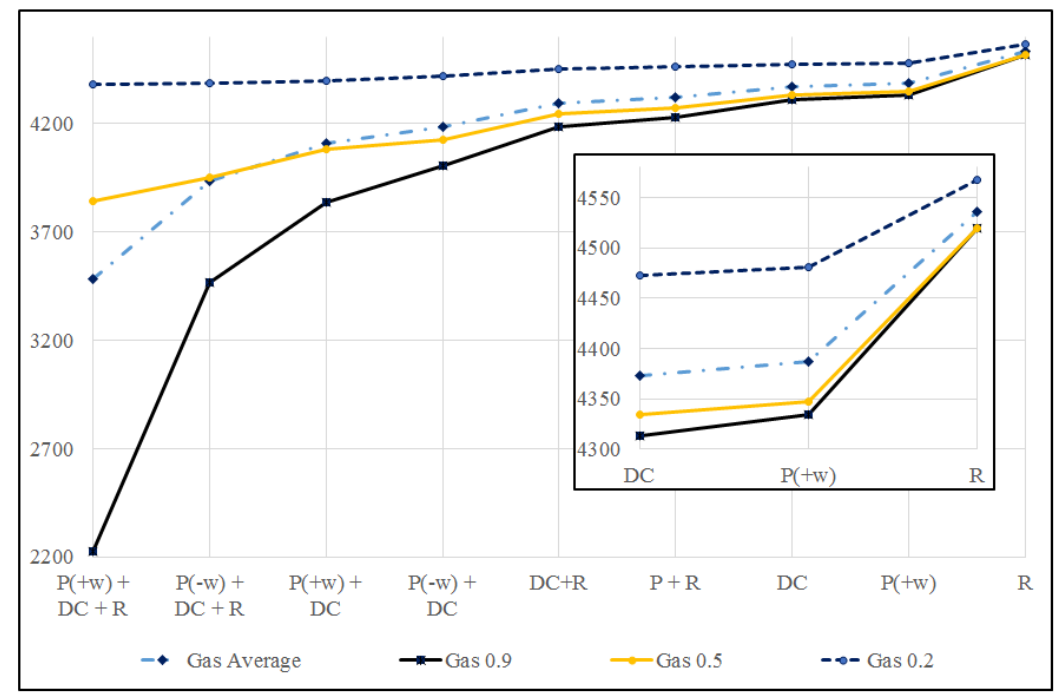

Figure 5. Average $\Delta$ turnover with 5-day gas disruption at different resilience levels 


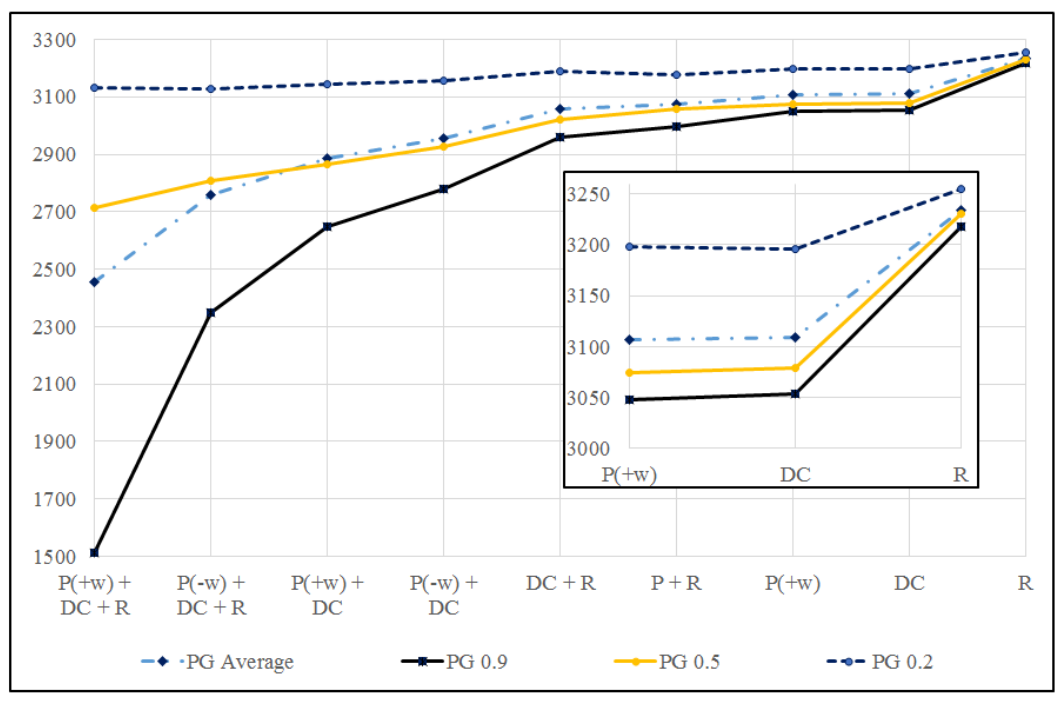

Figure 6. Average $\Delta$ turnover with 5-day power disruption at different resilience levels

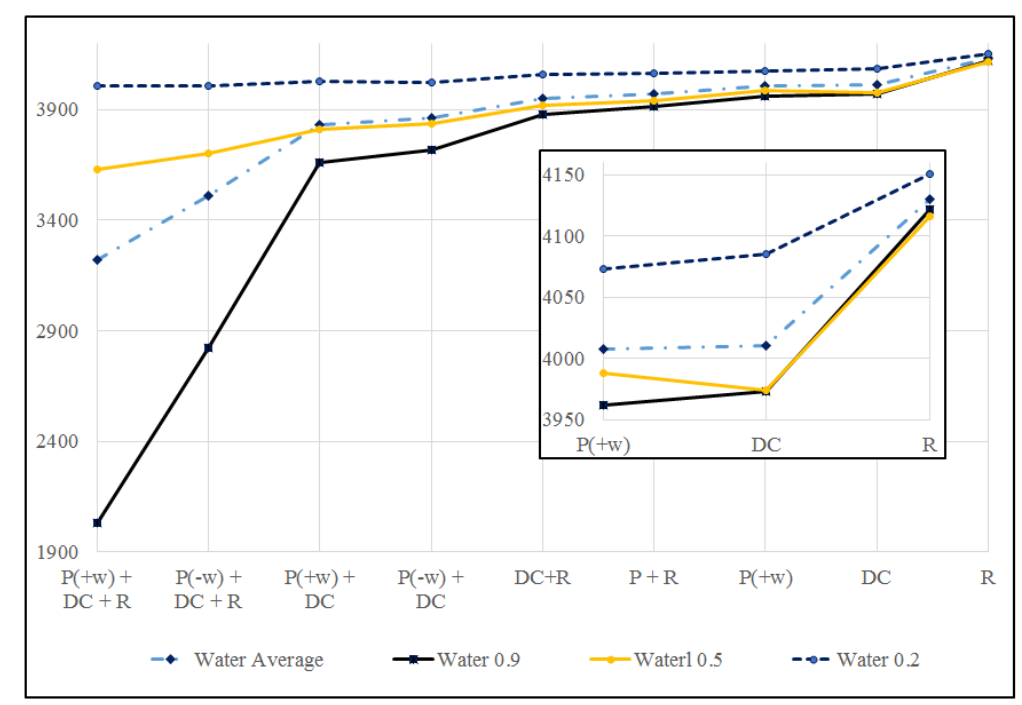

Figure 7. Average $\Delta$ turnover with 5-day water disruption at different resilience levels

Table 4. Summary of the simulation results - 5 days of $50 \%$ service loss from different CIs

\begin{tabular}{|c|c|c|c|c|c|c|c|c|c|c|c|c|c|c|c|}
\hline \multirow{3}{*}{$\begin{array}{l}\text { Actor(s) with } \\
\text { resilience } \\
\text { capabilities }\end{array}$} & \multicolumn{12}{|c|}{ Average $\Delta$ turnover from the baseline, at different resilience capability levels (ResLev) [M€] } & \multirow{2}{*}{\multicolumn{3}{|c|}{$\begin{array}{c}\text { Average recovered turnover } \\
\text { [\%] at different resilience } \\
\text { capability levels }^{\dagger}\end{array}$}} \\
\hline & \multicolumn{3}{|c|}{ Fuel } & \multicolumn{3}{|c|}{ Gas } & \multicolumn{3}{|c|}{ PG } & \multicolumn{3}{|c|}{ Water } & & & \\
\hline & 0.9 & 0.5 & 0.2 & 0.9 & 0.5 & 0.2 & 0.9 & 0.5 & 0.2 & 0.9 & 0.5 & 0.2 & 0.9 & 0.5 & 0.2 \\
\hline$\overline{\mathrm{P}(+\mathrm{w})+\mathrm{DC}+\mathrm{R}}$ & 1977 & 3605 & 3976 & 2226 & $\overline{3842}$ & $\overline{4384}$ & $\overline{1514}$ & 2715 & 3131 & 2032 & 3630 & 4005 & $52.2 \%$ & $\overline{15.0 \%}$ & $4.5 \%$ \\
\hline$P(-w)+D C+R$ & 3352 & 3744 & 4017 & 3470 & 3950 & 4388 & 2348 & 2806 & 3126 & 2823 & 3704 & 4008 & $26.1 \%$ & $12.5 \%$ & $4.2 \%$ \\
\hline $\mathrm{P}(+\mathrm{w})+\mathrm{DC}$ & 3619 & 3764 & 3998 & 3840 & 4084 & 4399 & 2648 & 2866 & 3145 & 3660 & 3811 & 4028 & $15.1 \%$ & $10.5 \%$ & $4.0 \%$ \\
\hline$P(-w)+D C$ & 3826 & 3868 & 4054 & 4006 & 4127 & 4420 & 2780 & 2927 & 3157 & 3718 & 3838 & 4025 & $11.7 \%$ & $9.0 \%$ & $3.5 \%$ \\
\hline $\mathrm{P}+\mathrm{R}$ & 3951 & 3969 & 4077 & 4230 & 4275 & 4462 & 2995 & 3056 & 3177 & 3915 & 3938 & 4064 & $7.0 \%$ & $6.1 \%$ & $2.7 \%$ \\
\hline $\mathrm{DC}+\mathrm{R}$ & 3907 & 3939 & 4069 & 4183 & 4244 & 4452 & 2960 & 3023 & 3187 & 3879 & 3917 & 4057 & $8.0 \%$ & $6.8 \%$ & $2.8 \%$ \\
\hline $\mathrm{P}(+\mathrm{w})$ & 3936 & 3943 & 4068 & 4334 & 4347 & 4481 & 3048 & 3074 & 3198 & 3962 & 3988 & 4073 & $5.8 \%$ & $5.4 \%$ & $2.5 \%$ \\
\hline DC & 3997 & 4009 & 4082 & 4313 & 4334 & 4473 & 3054 & 3079 & 3196 & 3973 & 3974 & 4085 & $5.5 \%$ & $5.1 \%$ & $2.4 \%$ \\
\hline $\mathrm{R}$ & 4101 & 4095 & 4124 & 4520 & 4519 & 4567 & 3218 & 3231 & 3255 & 4122 & 4116 & 4151 & $1.6 \%$ & $1.6 \%$ & $0.8 \%$ \\
\hline
\end{tabular}

Note: ${ }^{*} \mathrm{P}(+\mathrm{w})=$ Producer (with water included in the strategy); $\mathrm{P}(-\mathrm{w})=$ producer (with water not included in the strategy); DC=Distribution Centres; $\mathrm{R}=$ Retailers

${ }^{\dagger}$ Percentage values calculated as the ratio of the difference between average turnover at some ResLev and worst case scenario, and difference between baseline turnover and turnover at the same ResLev. 


\section{Discussion}

Resilience capacity of recovering $20 \%$ does not seem to be making a big difference when applied across the different combination of actors. The recovered turnover compared to worst situation is very small except for power generation which showed marginally better values (compare Figure 6 with Figures 4, 5 and 7). The specific location of this resilience capacity level in the supply chain does not seem to bring much difference as well; it is not much different if a supply chain actor or multiple actors, upstream or downstream the supply chain, had little resilience capacity. The maximum possible turnover recovered from worst case with ResLev $=20 \%$ (by multiple actors upstream the supply chain) on average across the disruptions in the different CI systems is only $4.5 \%$; the lowest is $0.8 \%$ (see Table 4 ). It is to be noted that this resilience capacity equals the minimum trigger level of disruption.

When it comes to a higher level of resilience capacity (ResLev=50\%), the benefit of all the strategies are far more significant compared to the previous scenario. Multiple supply chain members upstream the supply chain with this level of resilience can recover up to an average of $15 \%$ turnover compared to worst case. The minimum value of recovered turnover is $1.6 \%$, when the corresponding resilience capacity is located only at the retailer.

In the best resilience scenario, involving the highest level of resilience capacity (ResLev=90\%), improvements in turnover from worst case range from a minimum of around $1.6 \%$, when the resilience capacity is concentrated at the retailer, to a maximum of $52 \%$ granted by a mixed allocation of the resilience capacity throughout all the three SC members, included the capacity to overcome water shortage.

In general, the results of the study show a very high vulnerability of the FMCG SC when hit by the unavailability of some critical services; even with the highest (90\%) resilience strategies implemented and the capacities mobilised to offset for a disruption in CI systems, the average recoverable turnover is about $52 \%$ of the potential losses. It appears that there is a structural rigidity of the FMCG SC, mainly due to the strong dependence of all transport systems on energy. The results reveal that there is only limited room for making supply chains, and KRSC in particular, more resilient against electrical blackouts and energy disruptions in general.

As expected, the average turnover loss due to CI disruptions, compared to the baseline (no disrupted scenario), is lower for higher value of resilience compared to lower values, under all disruption scenarios and resilience strategies. This result is however limited to the benefits of resilience capacities in face of unavailable work force at a respective supply chain actor. 
Resilience strategies at multiple number of actors perform better than strategies with a similar capacity level allocated at fewer or one supply chain actor only (compare Figures 4-7). Furthermore, resilience capacities at the upstream of the supply chain (i.e. producer) are able to recover more turnover compared to a similar level of resilience capacity in the downstream. This result has at least two implications. First, SC resilience depends on a coordinated effort between different actors independently from the level of available capacity; second, this collaborative approach to improving SC resilience may lead to a rebalance in the value chain, since under widespread CI disruptions, retailers benefit from turnover recovery thanks to resilience capacities primarily implemented by producers and distribution centres.

Another observation is that multiple forms of resilience capacities perform better than a single type of resilience capacity at higher level. In our case, the capacity to offset water disruption in addition to other resilience capacities gave rise to recovery almost the same turnover compared to a much higher resilience capacity without mitigation strategies against water shortage; e.g. $\mathrm{P}(+\mathrm{w})+\mathrm{DC}$ at ResLev $=0.5$ is estimated to recover $11 \%$ of turnover loss, whereas $\mathrm{P}(-\mathrm{w})+\mathrm{DC}$ at ResLev $=0.9$ is expected to recover only $12 \%$ (see Table 4). This observation seems further strengthening the role of interdependence relationships in a systemof-systems resilience, not only those existing between CI systems and related services, but also those influencing the effectiveness of resources allocation within the supply chain.

\section{Conclusions}

The results achieved with the present study are of relevance for both science and practice. As for the scientific contribution, the study offers original results at both methodological and content levels. Research on the analysis and modelling of the dependencies between KRSC and CI is still limited, mostly if we consider the resilience research stream. The majority of modelling techniques require a large amount of detailed data that are difficult to collect; alternative solutions, demand less data but model the non-linear dynamics of CI disruptions and the consequent spread of cascading effects in a poorly detailed way. In the present study, we tested a multimethod approach that uses a combination of SD and DES; based on the achieved results, it is possible to conclude that it represents a good trade-off and a better choice to support high-level system design or strategic decisions on resource allocation and coordination towards better system resilience. In this regard, the proposed multimethod approach expands the extant literature on system-of-systems modelling, with the aim of better supporting the vulnerability and resilience analysis of global supply chains against their multifaceted dependence on a wide set of CI systems. From a methodological point of view, 
further research is encouraged to offer a broader set of test cases and a systematic comparison of different modelling strategies and combinations of methods, including ABM also. Indeed, the modelling approach implemented in the present study still suffers for some limitations:

- the contribution of tactical decisions made by different actors during the disruption event, and their direct influence on the evolution of the event are not taken into consideration;

- similarly, the impact of geographical interdependencies is not accounted for, since the current model is not able to address issues related to the topology of CI systems, and the location of different supply chain facilities as well.

When these elements are the most relevant for the specific study, then ABM simulation should be adopted to model actors' behaviours at both CI and KRSC levels, so as to account for the former; network-based and flow-based approaches to CI modelling should be used to accommodate for the latter (Ouyang, 2014).

Further developments at methodological level could also address:

- the extension of the simulation model to incorporate a cost index for different strategies and resilience capacities;

- the integration of a set of resilience indicators enabling a more comprehensive and detailed comparison of disruption scenarios and response strategies.

Indeed, just looking at the specific case application, there is wide room for further in-depth investigation of cascading effects between CI and the FMCG SC, to achieve a better understanding of the dynamics of bottlenecks within the FMCG SC under different scenarios and response strategies.

As for the specific application domain, with reference to the FMCG supply chain, the study offers some relevant and original insights toward a better understanding of the strength and dynamics of the coupling between KRSC and CI, and consequently on resilience improvement efforts. Firstly, the study made it clear that supply chains react in completely different ways under distributed or localised disruptions. Cascading effects within the CI layer, activated by existing interdependencies, clearly result into a dispersed impact at supply chain level despite the location and the possible limited extension of the triggering event. Consequently, the attempts to achieve higher supply chain resilience cannot concentrate on a limited number of nodes, neither on a set of isolated investments and actions. The nature and dynamics of supply chain disruptions induced by CI interdependencies call for more coordinated and collaborative resilience strategies, involving all the relevant actors of modern global supply chains. In this 
line, the study also gives justification and support to future research on organisational capabilities and operational coordination in the context of supply chain resilience. More specifically, further research is needed to better understand the specific roles and contributions that different actors may cover, as well as the type of support they should be granted of, within a collaborative response and recovery set up. Resilience capabilities of organisational nature, both intra- and inter-organisational, need to be better investigated and understood. Finally, larger studies are encouraged in future to overcome some of the limitations that affect the present study when it comes with modelling and quantifying the key processes and factors shaping the behaviour of CI. Indeed:

- some of the hypotheses at the basis of the CI model we adopted in the study are still simplistic, such as neglecting staff factor in power, water and gas facilities, so the assessment of critical service unavailability and the consequent turnover loss in the FMCG supply chain may not be accurate (underestimated);

- the quantification of the FMCG model was based on secondary and sector related data; to achieve better precision and reliability of results, more detailed data of confidential nature should be collected (e.g., actual stock location and product coverage, switch time and quantity between different mode of transports);

Supply chain managers may also benefit of the suggested prioritisation of resilience strategies, according to their estimated benefits, when making decisions on the amount and location of resilience capacities within KRSC, and the FMCG supply chain in particular. Again, the results of the present study strongly support managers' commitment and decisions in favour of collaborative or coordinated resilience practices among supply chain actors; as well as the adoption of advanced tools and solutions to get higher visibility of risks coming from vital services and related infrastructure.

\section{References}

Birkie, S. E., Trucco, P., \& Kaulio, M. (2014). Disentangling core functions of operational resilience: a critical review of extant literature. International Journal of Supply Chain and Operations Resilience, 1(1), 76103.

Brailsford, S., Churilov, L., \& Dangerfield, B. (Eds.). (2014). Discrete-Event Simulation and System Dynamics for management decision making. John Wiley \& Sons.

BSI (British Standards Institute). (2015). 2015 Security Risk Index. London: BSI Supply Chain Solutions.

Clarke, L., \& MacDonald, A. (2014, April 2). Copper ends slightly higher after jolt from Chile earthquake. Wall Street Journal. Retrieved from http://www.wsj.com/articles/SB10001424052702304157204579476440226661758

Conrad, S. H., LeClaire, R. J., O’Reilly, G. P., \& Uzunalioglu, H. (2006). Critical national infrastructure reliability modeling and analysis. Bell Labs Technical Journal, 11(3), 57-71. 
Craighead, C. W., Blackhurst, J., Rungtusanatham, M. J., \& Handfield, R. B. (2007). The severity of supply chain disruptions: Design characteristics and mitigation capabilities. Decision Sciences, 38(1), 131-156.

Fahimnia, B., Tang, C. S., Davarzani, H., \& Sarkis, J. (2015). Quantitative models for managing supply chain risks: A review. European Journal of Operational Research, 247(1), 1-15.

Hall, P. V. (2004). “We'd have to sink the ships”: Impact studies and the 2002 West Coast port lockout. Economic Development Quarterly, 18(4), 354-367.

INIS (Italian National Institute of Statistics). (2015). I.Stat. Retrieved from www.dati.istat.it.

Ivanov, D., \& Sokolov, B. (2013). Control and system-theoretic identification of the supply chain dynamics domain for planning, analysis and adaptation of performance under uncertainty. European Journal of Operational Research, 224(2), 313-323. http://doi.org/10.1016/j.ejor.2012.08.021

Ivanov, D., Sokolov, B., \& Dolgui, A. (2014). The Ripple effect in supply chains: Trade-off “efficiencyflexibility-resilience” in disruption management. International Journal of Production Research, 52(7), 2154-2172.

Kamalahmadi, M., \& Parast, M. M. (2016). A review of the literature on the principles of enterprise and supply chain resilience: Major findings and directions for future research. International Journal of Production Economics, 171(1), 116-133.

Kim, Y., Chen, Y., \& Linderman, K. (2015). Supply network disruption and resilience: A network structural perspective. Journal of Operations Management, 33-34, 43-59.

Kumar, S., \& Nigmatullin, A. (2011). A system dynamics analysis of food supply chains - Case study with nonperishable products. Simulation Modelling Practice and Theory, 19(10), 2151-2168.

MacKenzie, C. A., Santos, J. R., \& Barker, K. (2012). Measuring changes in international production from a disruption: Case study of the Japanese earthquake and tsunami. International Journal of Production Economics, 138(2), 293-302.

McNally, R. K., Lee, S.-W., Yavagal, D., \& Xiang, W.-N. (2007). Learning the critical infrastructure interdependencies through an ontology-based information system. Environment and Planning B: Planning and Design, 34(6), $1103-1124$.

Ouyang, M. (2014). Review on modeling and simulation of interdependent critical infrastructure systems. Reliability Engineering and System Safety, 121, 43-60. http://doi.org/10.1016/j.ress.2013.06.040

Owen, C., Albores, P., Greasley, A., \& Love, D. (2010). Simulation in the supply chain context: Matching the simulation tool to the problem. In Proceedings of the 2010 Operational Research Society Simulation Workshop (pp. 229-242).

Patterson, S. (2015, November 26). Water troubles in tiny Chilean town threaten global copper supply. Wall Street Journal. Retrieved from http://www.wsj.com/articles/scarcity-of-water-poses-challenge-for-copperminers-1448549196

Pidd, M. (2003). Tools for thinking: Modelling in management science (2nd ed.). John Wiley \& Sons.

Ponomarov, S. Y., \& Holcomb, M. C. (2009). Understanding the concept of supply chain resilience. The International Journal of Logistics Management, 20(1), 124-143.

Rice, J. B., \& Caniato, F. (2003). Building a secure and resilient supply network. Supply Chain Management Review, 7(5), 22-30.

Rinaldi, S. M., Peerenboom, J. P., \& Kelly, T. K. (2001). Identifying, understanding, and analyzing critical infrastructure interdependencies. IEEE Control Systems Magazine, 21(6), 11-25.

Santella, N., Steinberg, L. J., \& Parks, K. (2009). Decision making for extreme events: Modeling critical infrastructure interdependencies to aid mitigation and response planning. Review of Policy Research, 26(4), 409-422.

Sheffi, Y. (2007). The resilient enterprise: Overcoming vulnerability for competitive advantage. Cambridge, MA: MIT Press.

Sterman, J. (2000). Business dynamics: systems thinking and modeling for a complex world. McGraw-Hill. 
Tako, A. A., \& Robinson, S. (2012). The application of discrete event simulation and system dynamics in the logistics and supply chain context. Decision Support Systems, 52(4), 802-815.

Tang, C. S. (2006). Robust strategies for mitigating supply chain disruptions. International Journal of Logistics Research and Applications, 9(1), 33-45.

The Council of the European Union. (2008). Council Directive 2008/114/EC of 8 December 2008 on the indentification and designation of European critical infrastructures and the assessment of the need to improve their protection. Official Journal of the European Union, 75-82.

World Economic Forum. (2012). New models for addressing supply chain and transport risk. Industry Agenda. World Economic Forum.

Wu, D., \& Olson, D. L. (2008). Supply chain risk, simulation, and vendor selection. International Journal of Production Economics, 114(2), 646-655.

Wu, T., Huang, S., Blackhurst, J., Zhang, X., \& Wang, S. (2013). Supply chain risk management: An agentbased simulation to study the impact of retail stockouts. IEEE Transactions on Engineering Management, 60(4), 676-686.

Yang, T., \& Wu, J. (2007). The impact of transportation disruptions on performance of e-Collaboration supply chain. In L. Xu, A. Tjoa, \& S. Chaudhry (Eds.), IFIP International Federation for Information Processing, Vol. 256, Research and Practical Issues of Enterprise Information Systems II Vol. I (pp. 663667). Boston: Springer. 